\title{
Adaptive Control of DC-DC Converter Using Simulated Annealing Optimization Method
}

\author{
Amin Alqudah', Ahmad Malkawi², Abdullah Alwadie ${ }^{3}$ \\ ${ }^{1}$ Computer Engineering Department, Hijjawi Faculty for Engineering Technology, Yarmouk University, Irbid, \\ Jordan \\ ${ }^{2}$ Department of Electrical and Computer Engineering, Faculty for Engineering and Computer Science, Concordia \\ University, Quebec, Canada \\ ${ }^{3}$ College of Engineering, Najran University, Najran, KSA \\ Email: amin.alqudah@yu.edu.jo, ah.malkawi@outlook.com, alwadei@hotmail.com
}

Received 18 May 2013; revised 30 October 2013; accepted 10 November 2013

Copyright @ 2014 by authors and Scientific Research Publishing Inc.

This work is licensed under the Creative Commons Attribution International License (CC BY).

http://creativecommons.org/licenses/by/4.0/

(c) (i) Open Access

\section{Abstract}

The purpose of this paper is to present a new adaptive control method used to adjust the output voltage and current of DC-DC (DC: Direct Current) power converter under different sudden changes in load. The controller is a PID controller (Proportional, Integrator, and Differentiator). The gains of the PID controller $\left(K_{P}, K_{I}\right.$ and $\left.K_{D}\right)$ tuned using Simulated Annealing (SA) algorithm which is part of Generic Probabilistic Metaheuristic family. The new control system is expected to have a fast transient response feature, with less undershoot of the output voltage and less overshoot of the reactor current. Pulse Width Modulation (PWM) will be utilized to switch the power electronic devices.

\section{Keywords}

DC-DC Converter, PID Controller, Simulated Annealing

\section{Introduction}

DC-DC power converters are used in variety of application, including computer systems, office equipment, telecommunication equipment, and other electronics devices. DC-DC converters are electrical circuits that would transfer energy to a load. Electronic switches are used to transfer the energy to energy storage devices and then to load. In DC-DC converters, the switches are either transistors or diodes, whereas capacitors and inductors re- 
present the storage devices. The amount of voltage transferred depends on the duty ratios of the switches [1]. The switch is driven by a pulse width modulator PWM. The output signal of the PWM is controlled using a PID controller. The PID gains are tuned using Simulated Annealing optimizers (SA) to improve the transient response of the DC-DC converter.

The simulated annealing optimization method is a statistical optimization technique based on a wide random search to achieve global optimum solution with high probability [2]. The idea is based on mimicking the process of annealing a material and then slowly reducing its temperature until a state of thermal equilibrium, which is characterized by minimum energy.

\section{Literature Review}

Many researchers have worked in the field of controlling DC-DC conversion; in [3] the authors present an implementation of the dynamic evolution control with linear evolution path for boost DC-DC power converter. This method uses a simple analysis of non linear equation models of the converter to tune the converter controllers. This method is used for digital controller to obtain zero steady state error and wide range of stability.

The authors in [4] presented a genetic algorithm-based PID tuning to optimize the performance of the DC-DC converter. A cascade closed-loop control system was implemented consisting of two loops (outer voltage loop inner current loop). The genetic algorithm was used to optimize the gains of the PID controller for the voltage loop.

In [5], the paper conducted high current applications. A DC-DC converter of two stages was studied. The converter consists of two full-bridge inverters both three phase. In this converter a high power factor at the AC stage and a regulated voltage at the DC load are needed. To solve this issue, a control scheme is designed for both inverters. This control scheme is based on a switching function model.

The application of fuzzy control to DC-DC converters operating at finite switching frequency is compared with several control methods like hysteresis and sliding mode method. One of the disadvantages of this fuzzy control is there is no procedure for designing the control rule and the membership functions [6].

The paper in [7] describes a control design procedure for PWM DC-DC converters when there is a large variation in the input reference. The controller has two components: a linear feedback to improve transient response, and a nonlinear feed forward to reject large input disturbances.

\section{DC-DC Converter}

DC-DC converters are electronic devices used whenever we want to change DC electrical power voltage from one voltage level to another. They are needed because the DC voltage cannot be simply stepped up or down using a transformer as well as AC voltage [1].

Modern electronic systems require high-quality, small size, light-weight, reliable and efficient power supplies. DC-DC converters use power electronics semiconductor switches operating in "on" and "off” states and this is because there is a small power loss in those states; i.e. low voltage in the "on" state, and zero current in the "off” state. In order for the DC-DC converter to be smaller and lighter, the power electronic switches must operate on high operating frequencies. High operating frequencies allow achieving fast dynamic response to rapid changes in the load current and the input voltage [1].

\subsection{Step-Down Buck Converter}

The step-down DC-DC converter is known as the buck converter which is shown in Figure 1 . It consists of a dc input $V_{\text {in }}$, a controlled switch $S$, a diode $D$, an inductor $L$, a capacitor $C$, and a load resistor $R$.

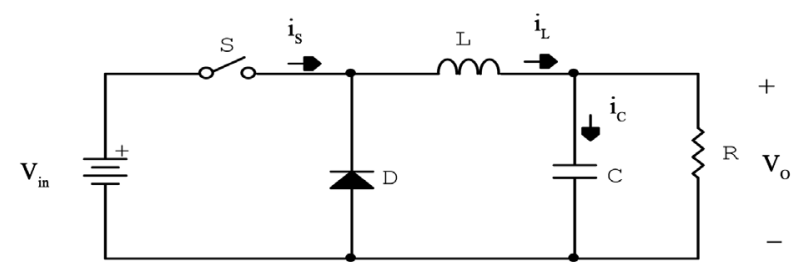

Figure 1. Buck converter circuit diagram. 
The switch $S$ is a unidirectional voltage and implemented with power MOSFETs. The relationship between the input and the output voltages and the switch duty ratio $D$ can be illustrated in the following formula with $T=1 / f \quad[8]$.

$$
\begin{gathered}
\left(V_{\text {in }}-V_{O}\right) D T=-V_{O}(1-D) T \\
\frac{V_{O}}{V_{\text {in }}}=D
\end{gathered}
$$

The buck converter operation can be divided into two periods; one of them when the switch is "on", and the other when it is "off" [8].

- In the "on" period:

The inductor current can be represented using by:

$$
\frac{\mathrm{d} i_{L}}{\mathrm{~d} t}=\frac{V_{i n}}{L}-\frac{V_{C}}{L}
$$

and the capacitor voltage can be represented by:

$$
\begin{gathered}
\frac{\mathrm{d} V_{C}}{\mathrm{~d} t}=\frac{i_{L}}{C}-\frac{V_{C}}{R C} \\
V_{O}=V_{C}
\end{gathered}
$$

- In the "off" period:

The inductor current can be represented by:

$$
\frac{\mathrm{di} i_{L}}{\mathrm{~d} t}=-\frac{V_{C}}{L}
$$

and the capacitor voltage can be represented by:

$$
\begin{gathered}
\frac{\mathrm{d} V_{C}}{\mathrm{~d} t}=\frac{i_{L}}{C}-\frac{V_{C}}{R C} \\
V_{O}=V_{C}
\end{gathered}
$$

where, $i_{L}$ is the current through the inductor, $V_{C}$ is the voltage across the capacitor, $V_{i n}$ is the DC input voltage and $V_{O}$ is DC output voltage.

The above equations can be rewritten in state space as:

During “on" time:

$$
\dot{x}=A_{1} x+b_{1} V_{i n} ; \quad V_{O}=q_{1} x
$$

During “off” time:

$$
\dot{x}=A_{2} x+b_{2} V_{i n} ; \quad V_{O}=q_{2} x
$$

where,

$$
\dot{x}=\left[\begin{array}{c}
\frac{\mathrm{d} i_{L}}{\mathrm{~d} t} \\
\frac{\mathrm{d} V_{C}}{\mathrm{~d} t}
\end{array}\right] ; \quad A_{1}=A_{2}=\left[\begin{array}{cc}
\frac{-1}{L} & \frac{-1}{L} \\
\frac{1}{C} & \frac{-1}{R C}
\end{array}\right] ; \quad b_{1}=\left[\begin{array}{c}
\frac{i}{L} \\
0
\end{array}\right] ; \text { and } b_{2}=\left[\begin{array}{l}
0 \\
0
\end{array}\right]
$$

Then from Equations (9) and (10):

$$
\frac{V_{O}(s)}{V_{i n}(s)}=\frac{M}{1+s \frac{L}{R}+s^{2} L C}
$$

where $M=D$. 


\subsection{Step-Up Boost Converter}

The step-up DC-DC converter is known as the boost converter which is shown in Figure 2. It consists of a dc input $V_{\text {in }}$, a controlled switch $S$, a diode $D$, an inductor $L$, a capacitor $C$, and a load resistor $R$. The switch $S$ is a unidirectional voltage and implemented with power MOSFETs.

The relationship between the input and the output voltages and the switch duty ratio $D$ can be illustrated in the following formula with $T=1 / f \quad$ [9].

$$
\begin{gathered}
V_{i n} D T=\left(V_{O}-V_{i n}\right)(1-D) T \\
\frac{V_{O}}{V_{i n}}=\frac{1}{1-D}
\end{gathered}
$$

The boost converter operation can be divided into two periods; one of them when the switch is "on", and the other when it is "off" [9].

- In the "on" period:

The inductor current is:

$$
\frac{\mathrm{d} i_{L}}{\mathrm{~d} t}=\frac{-R}{L} i_{L}+\frac{1}{L} V_{i n}
$$

and the capacitor voltage is:

$$
V_{C}=V_{O}=0
$$

- In the "off" period:

The inductor current is:

$$
\frac{\mathrm{d} i_{L}}{\mathrm{~d} t}=\frac{-R}{L} i_{L}-\frac{1-D}{L} V_{C}+\frac{1}{L} V_{i n}
$$

and the capacitor voltage is:

$$
\begin{gathered}
\frac{\mathrm{d} V_{C}}{\mathrm{~d} t}=\frac{1-D}{C} i_{L}-\frac{1}{R C} V_{C} \\
V_{O}=V_{C}
\end{gathered}
$$

where, $i_{L}$ is current through the inductor, $V_{C}$ is voltage across the capacitor, $V_{i n}$ is DC input voltage and $V_{O}$ is DC output voltage.

The above equations can be rewritten in state space as:

During “on" time:

$$
\dot{x}=A_{3} x+b_{3} V_{i n} ; \quad V_{O}=0
$$

During “off” time:

$$
\dot{x}=A_{4} x+b_{4} V_{i n} ; \quad V_{O}=q_{4} x
$$

where,

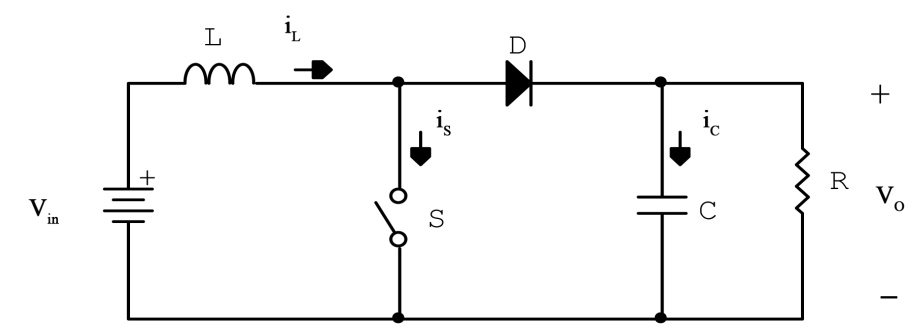

Figure 2. Boost converter circuit diagram. 


$$
\dot{x}=\left[\begin{array}{c}
\frac{\mathrm{d} i_{L}}{\mathrm{~d} t} \\
\frac{\mathrm{d} V_{C}}{\mathrm{~d} t}
\end{array}\right] ; \quad A_{3}=A_{4}=\left[\begin{array}{cc}
\frac{-R}{L} & -\frac{1-D}{L} \\
\frac{1-D}{C} & \frac{-1}{R C}
\end{array}\right] ; \quad b_{3}=b_{4}=\left[\begin{array}{c}
\frac{1}{L} \\
0
\end{array}\right]
$$

Then from the Equations (19) and (20)

$$
\frac{V_{O}(s)}{V_{i n}(s)}=\frac{M}{1+s \frac{L}{R}+s^{2} L C}
$$

where

$$
M=\frac{1}{1-D}
$$

\section{Control Principles}

A DC-DC converter must provide a regular DC output voltage under varying load and input voltage. The converter values change with time, temperature, and pressure so the controller should be a closed-loop controller with negative feedback. The voltage mode-controller is the most commonly used to control the pulse width modulator PWM [10], as shown in Figure 3.

In the voltage-mode controller the output voltage is sensed and converted to digital signal using ADC, then it is subtracted from a reference voltage to be fed to a controller; this will generate the control signal of the PWM and the PWM signal will drive the controllable switch (MOSFET) of DC-DC converter. The controller is a PID controller; a Simulating Annealing (SA) optimizer will be used to give an optimum PID controller gains. This will improve the transient response when there is a sudden change in the load of DC-DC converter.

\subsection{Simulated Annealing Optimizer}

Annealing is the process of heating solid bodies high temperature then allowing it to cool down. The mathematical equivalent of annealing is called simulated annealing and described in [2] [11].

The process of simulated annealing is represented based on the probability of Boltzmann distribution of energy $E$ at temperature $T$ as below [12]:

$$
p(E)=\alpha \mathrm{e}^{\frac{-E}{K T}}
$$

where

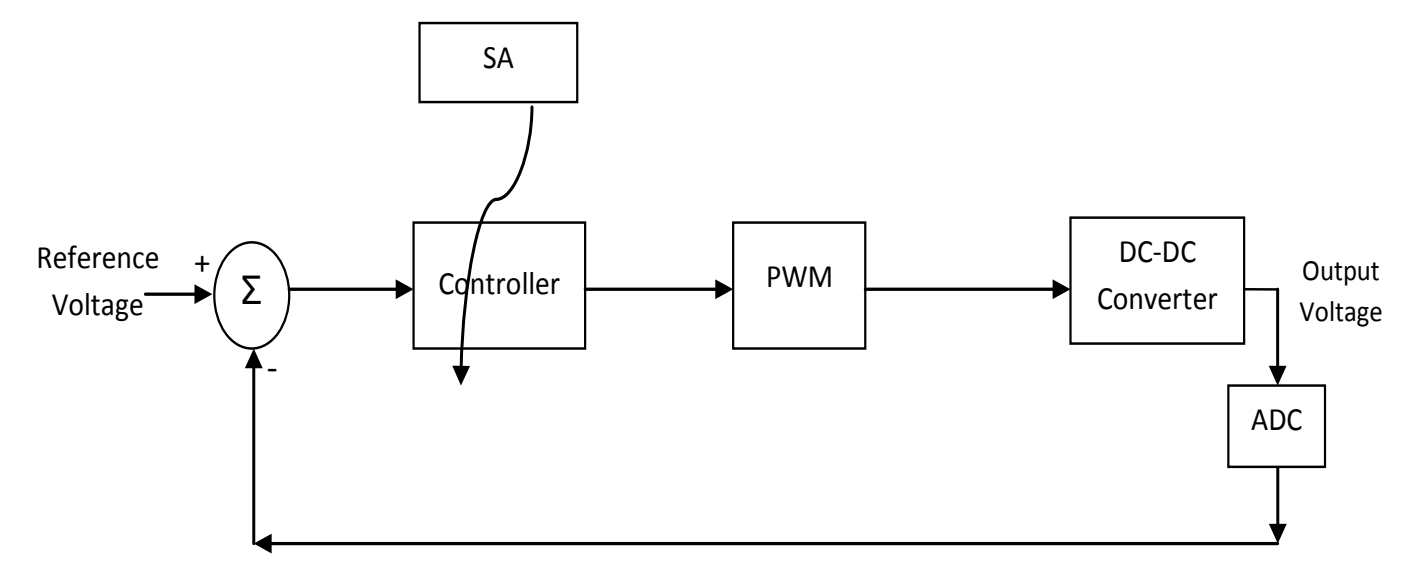

Figure 3. The control system of DC-DC converter. 


$$
\alpha=\frac{1}{K T}
$$

\subsection{Simulated Annealing Algorithm}

In this paper, Simulated Annealing is used to find the certain values of among a range of $(x, y$ and $z)$ in order to minimize a certain cost function $f(x, y, z)$. The SA algorithm can be summarized as follows [2] [11]:

Step 1: Set initial value of $T$.

Step 2: Select current set values of $x_{i}, y_{i}$ and $z_{i}$ from their ranges randomly.

Step 3: Compute the cost function $f\left(x_{i}, y_{i}, z_{i}\right)$.

Step 4: Select other values of $x_{i+1}, y_{i+1}$ and $z_{i+1}$ from the same ranges.

Step 5: Compute the cost function $f\left(x_{i+1}, y_{i+1}, z_{i+1}\right)$.

Step 6: If the $f\left(x_{i+1}, y_{i+1}, z_{i+1}\right) \leq f\left(x_{i}, y_{i}, z_{i}\right)$ then:

$$
\begin{aligned}
& x_{i}=x_{i+1} \\
& y_{i}=y_{i+1} \\
& z_{i}=z_{i+1}
\end{aligned}
$$

Step 7: If the $f\left(x_{i+1}, y_{i+1}, z_{i+1}\right)>f\left(x_{i}, y_{i}, z_{i}\right)$ then:

If the $\exp \left[\left(f\left(x_{i+1}, y_{i+1}, z_{i+1}\right)-f\left(x_{i}, y_{i}, z_{i}\right)\right) / T\right]>$ rand then:

$$
\begin{aligned}
x_{i} & =x_{i+1} \\
y_{i} & =y_{i+1} \\
z_{i} & =z_{i+1}
\end{aligned}
$$

Step 8: Reduce the temperature $T$.

Step 9: Repeat Step 3 to Step 8 for $n$ times to obtain the optimum solution.

Figure 4 shows the simulated annealing process described above.

In this work the cost function is:

$$
f\left(K_{p}, K_{i}, K_{d}\right)=\int_{0}^{T_{S}}|t e(t)| \mathrm{d} t
$$

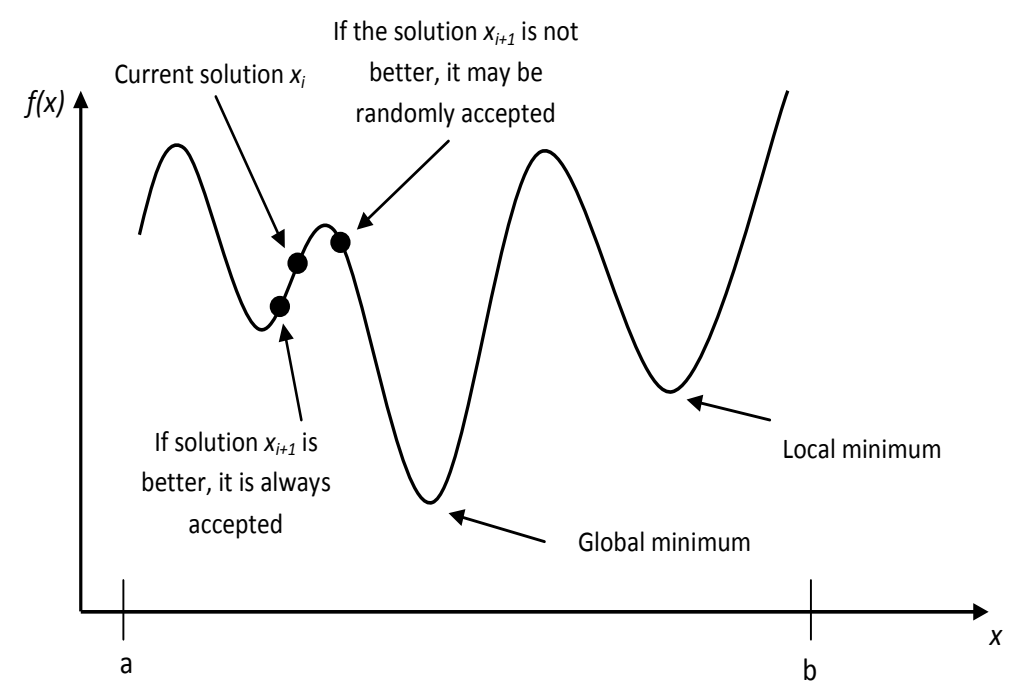

Figure 4. Simulated annealing process. 
where:

$$
e(t)=V_{O}(t)-V_{\text {in }}(t)
$$

\section{Results and Discussion [13]}

A simulated system of Buck and Boost DC-DC converter was built using MATLAB/SIMULINK toolbox. The DC-DC converter will be controlled using conventional PID controller and this controller will be tuned using Simulated Annealing optimizer. This is used to improve the transient response of the DC-DC converter.

In this work, the Simulated Annealing algorithm is used to tune the gains of the PID controller, which are used to adjust the output voltage and the reactor current. This reduces the undershoot, overshoot and settling time of the output voltage and reduces the overshoot of the reactor current as will be explained next.

\subsection{Step-Down Buck Converter Performance}

A simulated transient response of a Buck DC-DC converter was built using Matlab Simulink when the load $R$ changed from $100 \Omega$ down to $5 \Omega$. In this simulation the circuit parameters are as follow: $V_{\text {in }}=20$ volt, $V_{O}=5$ volt, $L=2 \mathrm{mH}, C=1000 \mu \mathrm{F}$ and the switching frequency $f=100 \mathrm{KHz}$.

Figure 5 shows the transient response for the conventional PID controller. As shown in the figure, the undershoot of the output voltage is $12.5 \%$, the overshoot of the output voltage is $17.3 \%$, the settling time is $14 \mathrm{~ms}$ and the overshoot of reactor current is $92.3 \%$.

Figure 6 shows the transient response for the Simulated Annealing optimizer. As shown in the figure, the undershoot of the output voltage is $10.4 \%$, the overshoot of the output voltage is $15.4 \%$, the settling time is 13 $\mathrm{ms}$ and the overshoot of reactor current is $82.9 \%$.

Table 1 compares the output based on the conventional PID and the SA output for Buck converter. As can be seen from the table, the output voltage undershoot was reduced, the output voltage over was also reduced. The settling time was slightly reduced and the reactor current over shoot was significantly reduced.

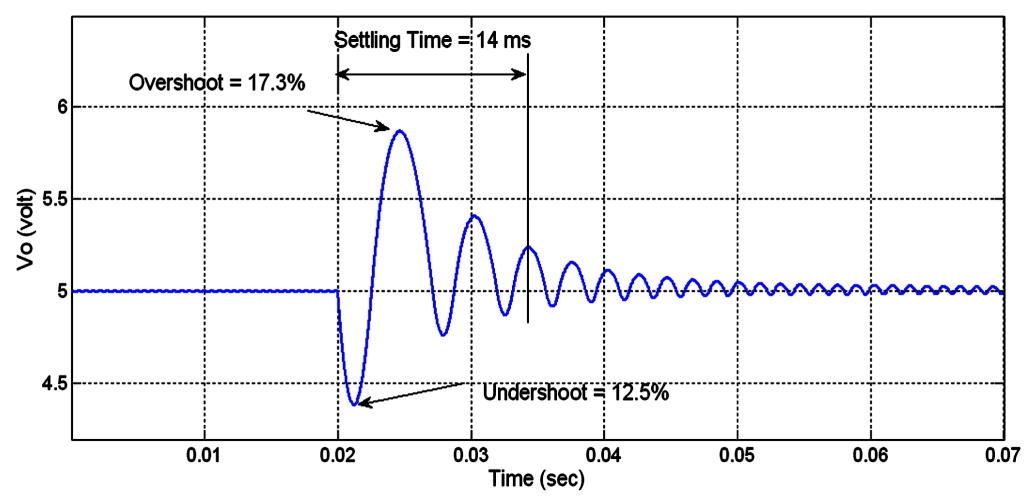

(a)

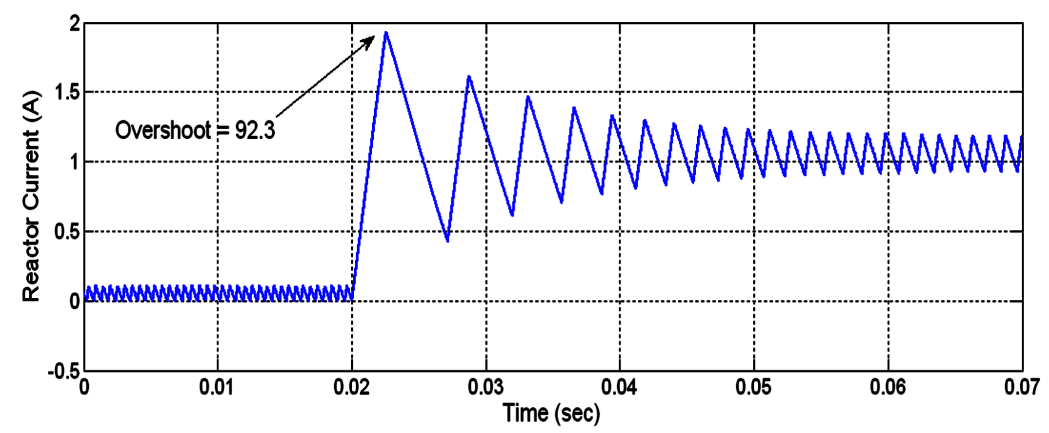

(b)

Figure 5. Transient response of conventional PID controller (a) Output voltage; (b) Reactor current. 


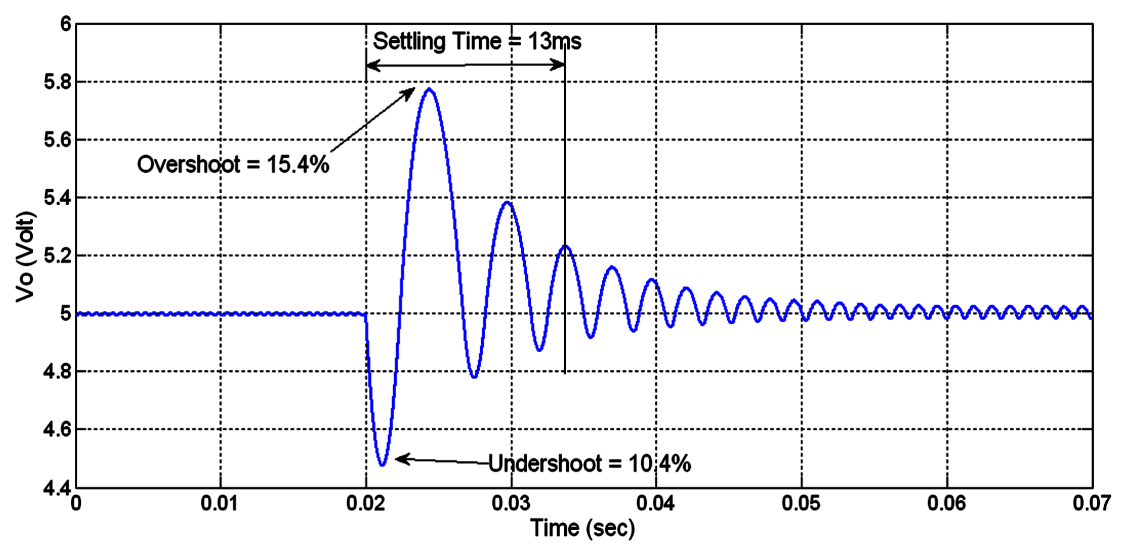

(a)

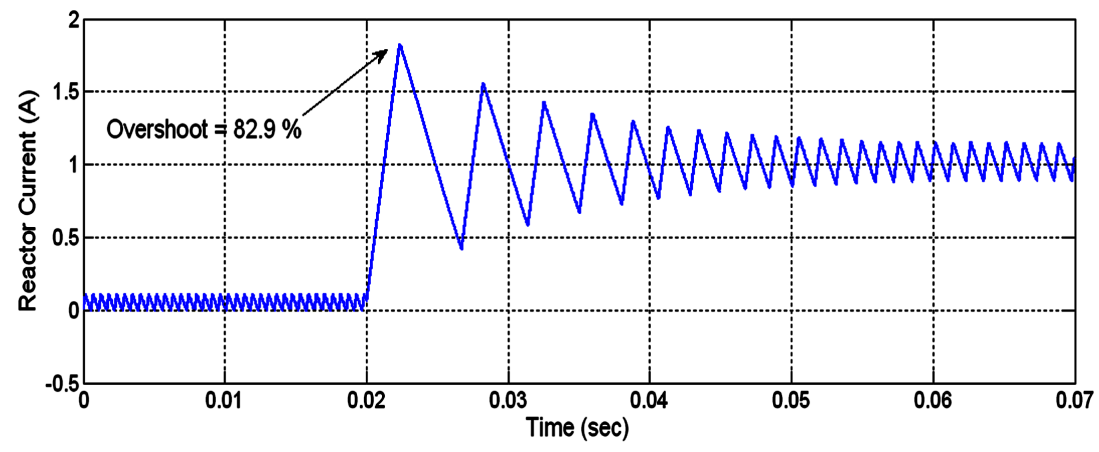

(b)

Figure 6. Transient response of the Simulated Annealing optimizer (a) Output voltage; (b) Reactor current.

Table 1. Conventional PID Vs SA output for Buck converter.

\begin{tabular}{cccc}
\hline & PID & SA & The improvement \\
\hline The output voltage undershoot & $12.5 \%$ & $10.4 \%$ & $16.8 \%$ \\
The output voltage overshoot & $17.3 \%$ & $15.4 \%$ & $11 \%$ \\
Settling time (ms) & 14 & 13 & $7.1 \%$ \\
The reactor current overshoot & $92.3 \%$ & $82.9 \%$ & $10.2 \%$ \\
\hline
\end{tabular}

\subsection{Step-Up Boost Converter Performance}

A simulated transient response of a Boost DC-DC converter was built using Matlab Simulink when the load $R$ changed from $100 \Omega$ down to $5 \Omega$. In this simulation the circuit parameters are as follow: $V_{\text {in }}=5$ volt, $V_{O}=10$ volt, $L=2 \mathrm{mH}, C=2000 \mu \mathrm{F}$ and the switching frequency $f=100 \mathrm{KHz}$.

Figure 7 shows the transient response for the conventional PID controller. As shown in the figure, the undershoot of the output voltage is $21.1 \%$, the overshoot of the output voltage is $9.9 \%$, and the overshoot of reactor current is $46.1 \%$.

Figure 8 shows the transient response for the Simulated Annealing optimizer. As shown in the figure, the undershoot of the output voltage is $19.8 \%$, the overshoot of the output voltage is $9.7 \%$, and the overshoot of reactor current is $45.5 \%$. As can be noticed, the improvement is minimal in this case.

Table 2 shows numerical comparison of the results embedded in Figure 7 and Figure 8. And again, seen from the table, the output voltage undershoot was reduced, the output voltage over was also reduced. The settling time was slightly reduced and the reactor current over shoot was slightly reduced as well. These results make the choice of the Boost converter not suitable for this control problem. 


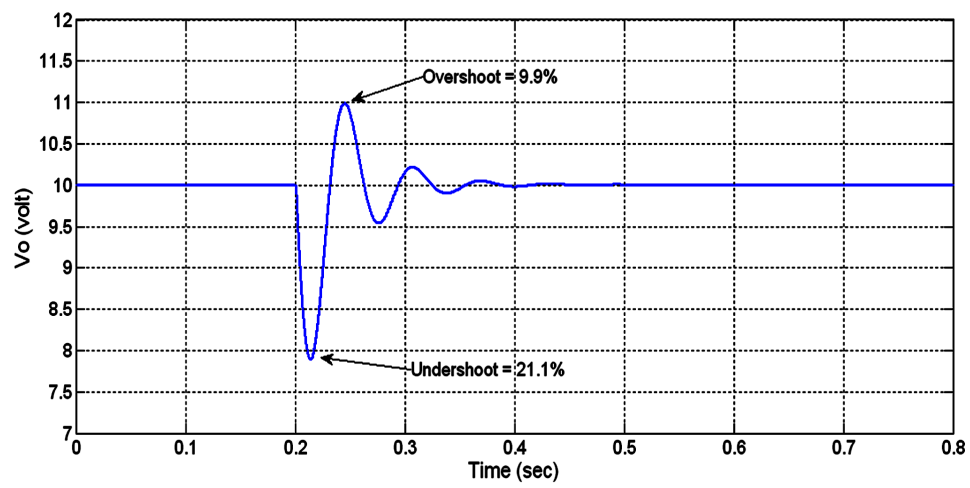

(a)

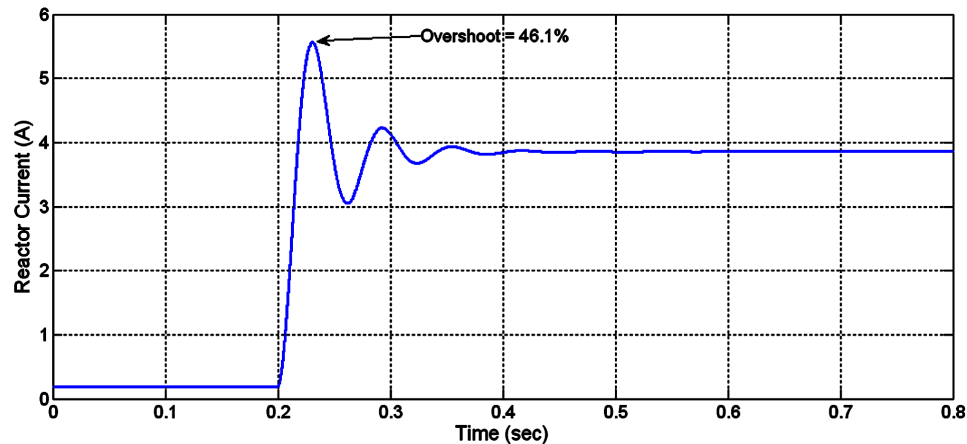

(b)

Figure 7. Transient response of conventional PID controller (a) Output voltage; (b) Reactor current.

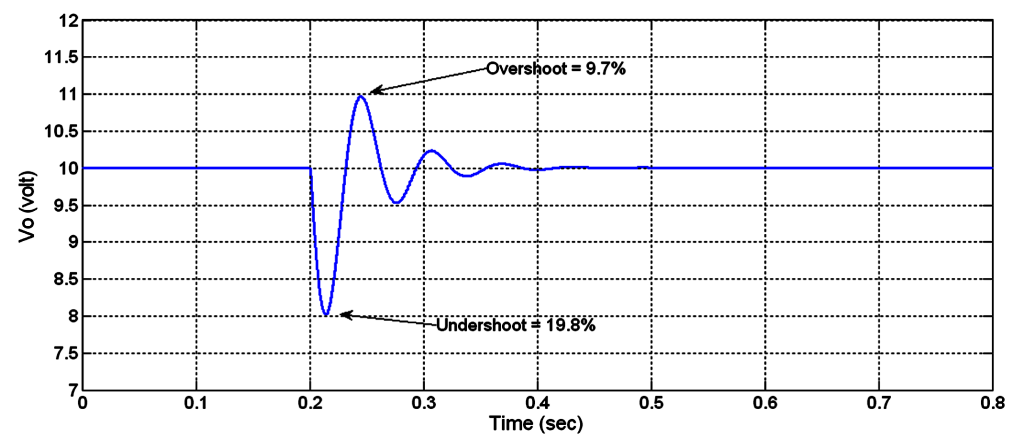

(a)

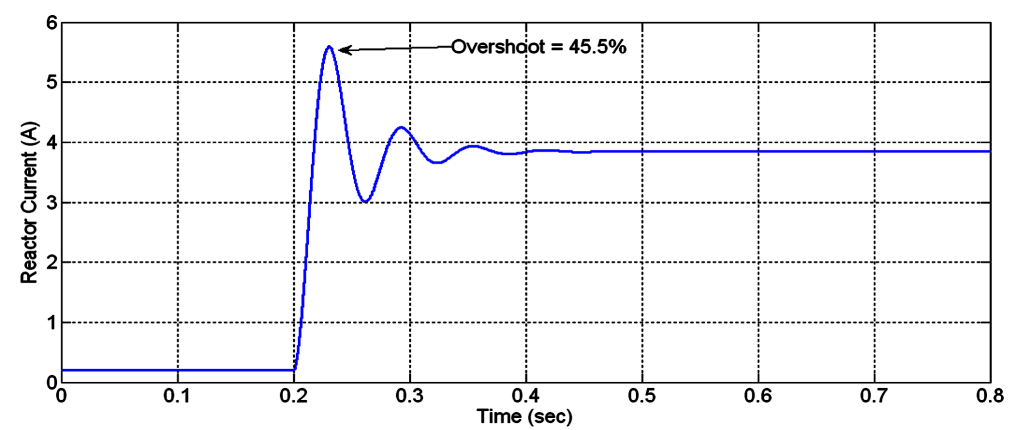

(b)

Figure 8. Transient response of the simulated annealing optimizer (a) Output voltage; (b) Reactor current. 
Table 2. Conventional PID Vs SA output for boost converter.

\begin{tabular}{cccc}
\hline & PID & SA & The improvement \\
\hline The output voltage undershoot & $21.1 \%$ & $19.8 \%$ & $6.2 \%$ \\
The output voltage overshoot & $9.9 \%$ & $9.7 \%$ & $2 \%$ \\
The reactor current overshoot & $46.1 \%$ & $45.5 \%$ & $2 \%$ \\
\hline
\end{tabular}

\section{Conclusions}

The DC-DC converter is a widely use power electronics circuit. The DC-DC converter output is affected by some parameters changes as load, input voltage, temperature, and the output voltage. So it is very important to use control system technique to improve the output response. One of the most control technique used is the PID controller. Designing a PID controller is complicated. Therefore, in this work we use the Simulated Annealing Optimizer (SA) to design and tune the PID controller gains.

Simulation results of two types DC-DC converters for sudden changes in the load are obtained. As shown in the simulation and results chapter, SA do an efficient improvement in the output in terms of the output voltage undershot, output voltage overshoot and the reactor current. Though, the buck converter got better results.

\section{References}

[1] Schimpfle, C.V. and Kirchner, J. (2003) A Step-Down Conversion Concept for a PWM-mode Boost Converter. IEEE Power Electronics, 963-968.

[2] Kirkpatrick, S., Gelatt Jr., C.D. and Vecchi, M.P. (1983) Optimization by Simulated Annealing. Science, 220, 671-680. http://dx.doi.org/10.1126/science.220.4598.671

[3] Samosir, A.S. and Yatim, A.H.M. (2008) Implementation of New Control Method Based on Dynamic Evolution Control with Linear Evolution Path for Boost Dc-Dc Converter. IEEE Power and Energy, 213-218.

[4] Wang, X.F., Wu, M., Ouyang, L.Y. and Tang, Q.S. (2008) The Application of GA-PID Control Algorithm to DC-DC Converter. IEEE Control, 3492-3496.

[5] Kanaan, H.Y., Al-Haddad, K., Georges, S. and Mougharbel, I. (2011) Design, Modelling, Control and Simulation of a Threephase DC-DC Converter for High Currents Applications. IEEE Power Electronics, 424-434.

[6] Lin, B.-R. (1993) Analysis of Fuzzy Control Method Applied to DC-DC Converter Control. IEEE Power Electron, 2228.

[7] Garofalo, F., Marino, P., Scala, S. and Vasca, F. (1994) Control of DC-DC Converters with Linear Optimal Feedback and Nonlinear Feedforward. IEEE Power Electronics, 607-615.

[8] Zhang, Y.C. and Hu, Y.M. (2008) On PID Controllers Based on Simulated Annealing Algorithm. Chinese Control Conference, 225-228.

[9] Jeong, G.-J., Kim, I.-H. and Son, Y.-I. (2009) An Adaptive Controller for a DC-DC Boost Converter Considering Load Variation and Coil Magnetic Saturation. APAP Power Electronics, 1-6.

[10] Rashid, M.H. (2011) Power Electronics Handbook. Elsevier Inc., USA.

[11] Kim, Y. and Kim, H. (1990) A Stepwise-Overlapped Parallel Simulated Annealing Algorithm, Integration. The VLSI Journal, 10, 39-54. http://dx.doi.org/10.1016/S0167-9260(05)80034-3

[12] Corana, A., Marchesi, M., Martini, C. and Ridella, S. (1987) Minimizing Multimodal Functions of Continuous Variables with the Simulated Annealing Algorithm. ACM Transactions on Mathematical Software, 262-280. http://dx.doi.org/10.1145/29380.29864

[13] Malkawi, A. (2012) Adaptive Control of the DC-DC Converter Using Simulated Annealing Optimization Method. M.Sc. Thesis, Yarmouk University, Irbid. 
Scientific Research Publishing (SCIRP) is one of the largest Open Access journal publishers. It is currently publishing more than 200 open access, online, peer-reviewed journals covering a wide range of academic disciplines. SCIRP serves the worldwide academic communities and contributes to the progress and application of science with its publication.

Other selected journals from SCIRP are listed as below. Submit your manuscript to us via either submit@scirp.org or Online Submission Portal.
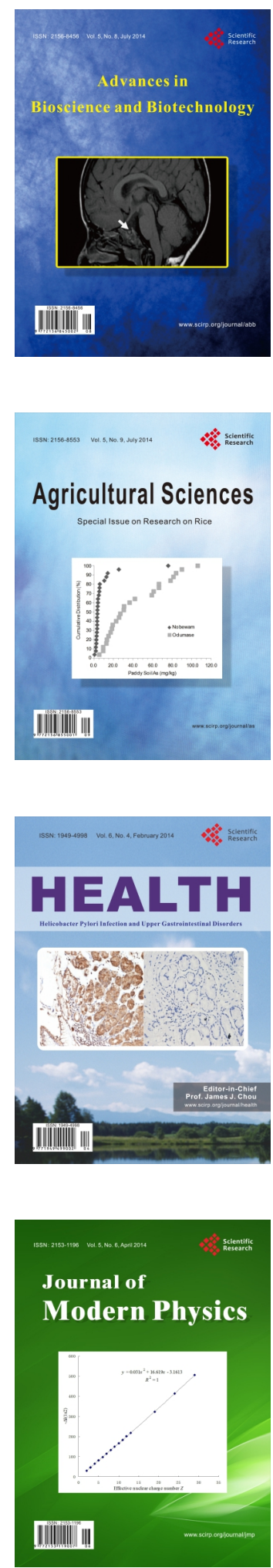
